\title{
Design e emoção: métodos e técnica para avaliação emocional de bens de moda
}

Carina Santos Silveira

Doutora, Universidade Federal da Bahia e Universidade do Estado da Bahia/ carinassilveira@gmail.com Orcid: 0000-0001-5266-1204/lattes

Suzi Maria Carvalho Mariño

Doutora, Universidade Federal da Bahia/ suzimarino@gmail.com Orcid: 0000-0001-8869-2299

Enviado: 31/05/2019 // Aceito: 16/08/2019 


\title{
Design e emoção: métodos e técnica para avaliação emocional de bens de moda
}

\begin{abstract}
RESUMO
Neste artigo, promove-se a apresentação de método e técnicas para o estudo emocional de usuários de produtos, com recorte de pesquisa para os bens de moda. De forma descritiva e aplicada, será abordado o método de engenharia kansei, que permite compreender as emoções que usuários atribuem à posse ou ao uso dos bens de moda. Como suporte, indicam-se a técnica de grupo focal, que objetiva a discussão sobre a moda com a consequente seleção de dados a serem utilizados no método, e a técnica de construção e aplicação da escala de diferencial semântico, utilizada no registro das impressões emocionais de usuários. Os resultados alcançados com a aplicação do método associado a essas técnicas visam a apresentar a relação da percepção emocional dos entrevistados com os elementos de design dos bens de moda que compõem uma estrutura vestimentar. Passa-se, desse modo, a entender que os significados emocionais atribuídos pelos usuários aos produtos podem ser compreendidos e convertidos em requisitos projetuais para o desenvolvimento de novos produtos. O método apresentado, associado às referidas técnicas, é considerado eficiente e passível de ser integrado à prática projetual do designer.
\end{abstract}

Palavras-chave: design emocional. Moda. Metodologia de projeto. 


\title{
Design and emotion: methods and technique for emotional evaluation of fashion goods
}

\begin{abstract}
The presentation of methods and techniques for the emotional study of products is proposed, with a clipping of research for fashion goods. The kansei engineering method will be explored in a descriptive and applied way, to help understand the emotions that users confer on products. Using focus group techniques, the objectives are to discuss the fashion and consequent selection of data to use with the method. In addition, the construction and application of the semantic differential scale will be used to record users' emotional impressions. The results, obtained with the applied method associated with the techniques; aim to present the relationship between the interviewees' emotional perception and design elements of the fashion goods that compose a clothing structure. Hence, the emotional significance attributed by users to products can be understood and converted into design requirements to develop new products. The presented method associated to the techniques is considered efficient and may be integrated to the practice of design.
\end{abstract}

Keywords: emotional design. Fashion. Project methodology. 


\title{
Diseño y emoción: métodos y técnicas para la valoración emocional de artículos de moda
}

\begin{abstract}
RESUMEN
En este artículo, se promueve la presentación de métodos y técnicas para el estudio emocional de los usuarios de productos, con un enfoque en la investigación de artículos de moda. De manera descriptiva y aplicada, se abordará el método de ingeniería kansei, que permite comprender las emociones que los usuarios atribuyen a la posesión o uso de artículos de moda. Como soporte, se indica la técnica del grupo focal, que tiene como objetivo discutir la moda con la consiguiente selección de datos que se utilizarán en el método, y la técnica de construcción y aplicación de la escala diferencial semántica, utilizada para registrar impresiones emocionales. de usuarios. Los resultados logrados con la aplicación del método asociado con estas técnicas tienen como objetivo presentar la relación de la percepción emocional de los entrevistados con los elementos de diseño de los artículos de moda que conforman una estructura de ropa. De esta manera, se entiende que los significados emocionales atribuidos por los usuarios a los productos se pueden entender y convertir en requisitos de diseño para el desarrollo de nuevos productos. El método presentado, asociado a las técnicas referidas, se considera eficiente $y$ puede integrarse en la práctica de diseño del diseñador.
\end{abstract}

Palabras clave: diseño emocional. Moda. Metodología de diseño. 


\section{Moda e design emocional}

A moda é uma forma de expressar emoções e história através de valores estéticos. A moda "fala". Ela se comunica por meio da organização visual de formas, tecidos, linhas, cores, estampas e volumes, caracterizando-se como uma expressão social própria, delimitada geográfica ou convencionalmente. A indumentária é uma dimensão constituinte do indivíduo e influencia em seu processo de socialização, traduzindo-se como uma linguagem única, particular, e como um elemento mediador do indivíduo, com sua cultura e identidade. Conforme Cidreira (2006), na perspectiva semiológica de Barthes (1979), a língua e a fala, transpostas para o universo da moda, correspondem a costume e vestuário. O costume (língua) corresponde a uma instituição social independente do indivíduo, e o vestuário (fala) a uma realidade particular de se expressar, uma manifestação atualizada da instituição geral do costume. Para o autor, dessa forma, faz-se distinção entre a vestimenta imagem, aquela que pode ser desenhada e fotografada, e a vestimenta escrita, que é a transformação da indumentária em linguagem produtora de significados, modos, costumes e identidade.

O vestir excede o prazer de um indivíduo na interação com a roupa, seus acessórios e volumes, suas cores e formas, pois aproxima e perpetua gerações a partir de aspectos físicos e afetivos. Na interação humana, a configuração visual da estrutura vestimentar - com a ordenação dos elementos de design e composição do estilo - é vista e decodificada através do repertório imagético e da imaginação do indivíduo observador, contemplando o processo de apreensão, significação e comunicação. Dotado de referências emocionais influenciadas por fatores objetivos e subjetivos o ser humano 
pauta sua expectativa para a vida e para tudo que o cerca, não sendo diferente a relação que mantém com os bens de moda.

As emoções sempre desempenharam um papel essencial na vida humana, tanto na prática de ações de sobrevivência, como no posicionamento histórico e social.

Todas as interações humanas envolvem emoções, incluindo as interações com o mundo material. Essa interação é um dos modos pelos quais a individualidade se constrói e se exerce, dentro de um espectro de escolhas a que os indivíduos ou grupos têm acesso em determinado momento histórico de uma sociedade. [...] Quanto mais o designer for sensível às questões atitudinais do destinatário e competente para tratá-las, mais será possível serem desenvolvidos produtos que possam interagir com as pessoas do modo emocional pretendido. (NIEMEYER, 2008, p. 56).

O conceito de emoção vem sendo compreendido de modo a buscar sua aplicação fundamentada no desenvolvimento de produtos. Faz-se necessária sua compreensão como um fenômeno afetivo particular e/ou coletivo, que direciona um cérebro autônomo e as mudanças de comportamento, promovendo a resposta a um evento externo ou interno, ou produto de significância. As emoções interferem na seleção, aquisição e uso dos produtos que estão ao alcance dos indivíduos.

As emoções causadas pelas interações com um produto podem ser influenciadas por fatores como estética, funcionalidade, marca, entre outros, além de serem complexas, pessoais, mutáveis, temporais e culturalmente dependentes. Podemos entender as emoções como reações afetivas que, pela sua intensidade, nos mobilizam para algum tipo de ação. (FONTOURA; ZACAR, 2008, p. 30) 
O produto criado através do design deve proporcionar ao usuário eficácia e eficiência em seu uso, na promoção de uma satisfação ou atendimento ao sentido do prazer. Tal prazer não está vinculado apenas ao conforto na interação com o produto, mas também à percepção de atendimento a necessidades individuais, como a interação social, a realização pessoal de um desejo, dentre outras. Para Fontoura e Zacar (2008), o produto carrega em si características e propriedades que estimulam e provocam associações nos indivíduos - uma diversidade de emoções que experimentam, a partir das quais passam a atribuir significado a esses produtos.

Desse modo, a pesquisa é motivada pelo "novo" comportamento social instaurado pelo atendimento de necessidades pautadas pelas experiências emocionais, nas quais o sentir passa a ser privilegiado, numa era em que as imagens falam mais e aproximam produto e indivíduo, indivíduo e indivíduo, estabelecendo uma relação identitária com o entorno. Tal sentir e as representações visuais constituem um plano de expressão e um legado cultural.

A moda, como discurso, é conduzida por seus elementos visuais e nos oferece a possibilidade de pensar nas transformações humanas, individuais e sociais, e de reescrevê-las através de novos significados - agora emocionais, para o atendimento desse "novo" comportamento social. Portanto, objetiva-se, neste artigo, apresentar métodos e técnicas utilizados no âmbito do design para identificar e compreender a relação emocional com produtos de moda. 


\section{Base conceitual do design emocional}

Diversos são os autores que abordam teorias da emoção ${ }^{1}$. Alguns deles estabelecem uma relação enfática entre a mente emocional e a racional na tomada de decisões, considerando a condução humana para interagir com produtos. Para o design emocional, cabe compreender as funções cognitivas, afetivas e volitivas que afetam a interação humana com os produtos. A função cognitiva, relacionada a pensamento, memória, raciocínio e percepção, é aquela que possibilita ao indivíduo a compreensão de mundo, sendo moldada socialmente e conduzida por percepções pessoais. Afetada pelo mundo exterior, a função afetiva se realiza quando o indivíduo experimenta situações diversas. Ela tem caráter subjetivo e permite a expressão de sentimentos ${ }^{2}$. A função volitiva diz respeito ao comportamento exteriorizável, isto é, à reação corporal ao estímulo dado pela função afetiva. Ilustrando com o objeto de estudo proposto, a moda expressa, através da estrutura vestimentar (composição de peças de vestuário e de adorno), uma relação cognitiva com cores, formas e volume que pode ser associada com as lembranças dos usuários. Tais lembranças despertam sentimentos (positivos ou negativos) expressos por uma reação de fala, de gestos, de movimentos corporais ou até mesmo de uma decisão sobre a estrutura vestimentar - usar ou não usar, gostar ou não gostar.

As emoções fazem parte do processo de raciocínio e interferem diretamente na tomada de decisão. Autores asseveram que as emoções conduziram a evolução humana no que tange à manutenção de sua sobrevivência e que o cérebro emocional "domina" o cérebro racional na tomada de decisões. 
[...] ela [a emoção] abre a possibilidade de levar seres vivos a agir de maneira inteligente sem precisar pensar com inteligência. [...] $\mathrm{O}$ raciocínio faz o que fazem as emoções, mas alcança 0 resultado conscientemente. $O$ raciocínio nos dá a opção de pensar com inteligência antes de agir de maneira inteligente, e isso é bom: descobrimos que muitos dos problemas que encontramos em nosso complexo ambiente podem ser resolvidos apenas com emoções, porém não todos, e nestas ocasiões as soluções que a emoção oferece são, na realidade, contraproducentes (DAMÁSIO, 1996, p. 27).

Dentro da perspectiva de que o homem se diferencia emocionalmente dos demais animais, Norman afirma que a emoção está sempre possibilitando a formulação de juízos de valor e apresentando informações imediatas a respeito do mundo. Assim, ele sustenta a ideia de que a emoção sempre foi o fator primaz na condução das decisões humanas de sobrevivência ou de comportamento. "O sistema afetivo faz julgamentos e rapidamente ajuda você a determinar as coisas no ambiente em que são perigosas, boas ou más. O sistema cognitivo interpreta e explica o sentido lógico do mundo" (NORMAN, 2008, p. 31).

A seleção de respostas, conforme regulação biológica cerebral, é uma forma elementar de "tomada de decisão, desde que fique bem claro que não se trata de um eu consciente que efetua a decisão" (DAMÁSIO, 1996, p. 144). O autor afirma que as decisões mal tomadas se dão pela perda do acesso ao que foi emocionalmente aprendido na vida de um indivíduo, sugerindo um ponto de interseção entre a emoção e o pensamento racional.

Goleman (1996) aponta para uma mente emocional que funciona por uma lógica associativa, em que os elementos que simbolizam uma dada realidade ou que, de alguma forma, lembram essa realidade são a própria realidade - o repertório emocional ${ }^{3}$. Os símbolos, metáforas, ritos e signos, verbais ou 
não verbais, que podem não fazer muito sentido para a mente racional, são "representações vernaculares de acesso ao coração" (GOLEMAN, 1996), isto é, são facilmente aceitas pela mente emocional. São estímulos primários para dar significação a algo, o que faz a mente emocional considerar tal significação como verdadeira.

Outro aspecto relevante na relação emocional dos indivíduos com os produtos que os cercam reside na busca pelo prazer. Para Jordan (1996), as pessoas estão em busca por algo mais nos produtos, não os considerando meramente como ferramentas funcionais e usáveis, mas buscando um relacionamento mais íntimo e afetivo com eles. Através dessa relação e da hierarquia das necessidades humanas, Jordan propõe que requisitos projetuais, associados à prática do designer no desenvolvimento de novos produtos, sejam hierarquizados em requisitos funcionais de usabilidade e de prazer. No entanto, salienta que o prazer não diz respeito exclusivamente ao produto, mas surge da relação do produto com o usuário.

A abordagem por projeto de produtos prazerosos caminha associada ao desafio de compreender as pessoas holisticamente. Tal abordagem implica: "ir além do olhar para fatores que influenciam o sucesso - em termos de conclusão de tarefas", como pontua Jordan (1996); compreender como as pessoas usam os produtos bem como o papel mais amplo que desempenham na vida delas; ser capaz de definir especificações do produto que vão além das especificações tradicionais, vinculando os prazeres às suas propriedades; e, por fim, "ligar" esses prazeres ao produto.

O design, a memória e a emoção apresentam razões para que os produtos marquem a vida humana. Desse modo, é possível traçar perspectivas projetuais nesse contexto. Compreende-se que "as emoções surgem da interface entre a 
ativação, expressão de comportamento e experiência consciente" (MYERS, 2006, p. 308). A resposta emocional, constituída pela reação do indivíduo frente aos estímulos, conduzirá o nível de interação com os produtos, atribuindoIhes valor diferenciado, independentemente do valor dado de modo racional.

Numa visão contemporânea, o produto, além de seus requisitos práticos, funcionais e estéticos, agrega uma conduta cognitiva que vai além do pensar - o sentir. Os aspectos sígnicos são inseparáveis da essência de um objeto, e a própria característica da funcionalidade carrega significado em si. Na aquisição de um novo produto, ou ainda na manutenção relacional com produtos antigos, os sujeitos contemporâneos não mais primam pelo atendimento às necessidades básicas, pois buscam algo mais: uma satisfação pessoal relacionada à emoção. Buscam produtos que os emocionem.

\section{Método de estudo da interação emocional do produto}

Como já foi visto, o foco no desenvolvimento de novos produtos passou a ter um olhar diferenciado para os aspectos emocionais da relação com o usuário, na busca do atendimento às suas necessidades implícitas, que são difíceis de mensurar e traduzem fatores que contribuem para sua satisfação. A emoção provocada pelo produto passa a ser o principal aspecto da satisfação do consumidor. Pelo exposto, foi no final do século XX que muitos estudiosos buscaram métodos e técnicas que pudessem ser atrelados à prática metodológica projetual do designer. Dentre tais métodos e técnicas, podem ser citados: 
a) observação da interação do usuário com o produto, como perfil de personalidade do produto, painel de tema visual, personagem-símbolo (creating a persona), método SEQUAM (Bonapace);

b) modelos baseados em pesquisa de mercado, como análise conjunta (Green e Srinivassan, 1990), Voice of Customer (Griffin e Hauser);

c) avaliação da interação emocional do usuário com o produto, como o disco das emoções (Scherer), sentimento analysis (Pang e Lee), PrEmo - product emotion measure (Desmet), modelo de referências de emoções (Scolari), Modelo de Análise do Design Emocional (Maxwell) e o método Kansei (KE).

Embora os métodos acima citados se assentem no mesmo objetivo - avaliar a interação emocional das pessoas com objetos, o kansei ou KE, segundo Lokman (2010), é um dos poucos métodos que abordam, especificamente, as necessidades implícitas dos usuários para com os produtos, de modo a guiar um projeto pautado em emoções. "A abordagem de engenharia Kansei é considerada como sendo a metodologia superior aos outros métodos similares, a mais confiável e útil para lidar com os requisitos emocionais dos consumidores (CHEN et al., 2008 e HARTONO; CHUAN, 2011 apud BALDUINO, 2012). E estudiosos como o próprio Nagamachi, Matsubara (1999) e Ishihara (2005) ainda defendem a preocupação do método com a cultura e o comportamento social entre indivíduos e nações onde o KE é aplicado, tornando-o um método global e adaptável.

$\mathrm{O}$ método $\mathrm{KE}$, associado à escala de diferencial semântico e à coleta de dados por grupo focal, pode se constituir num método aplicável à compreensão da relação emocional e semântica de usuários com produtos. Aqui abordaremos a descrição da metodologia aplicável aos bens de moda. 


\subsection{O método kansei (KE)}

Influenciado pelos estudos do filósofo alemão Baumgarten, em 1750, intitulados Aesthetica, Mitsuo Nagamachi desenvolve, na década de 1970 do século passado o método Kansei Engineering (KE). Na década de 90, o método passa a ser difundido e utilizado nas mais diversas áreas do conhecimento. O KE é classificado como um método da área da engenharia afetiva, segundo Lee, Harada e Stappers (2002 apud JÚNIOR; BENASSI; AMARAL, 2011). Conceituado por diversos autores como um método que busca, na relação do indivíduo com objetos, ambientes e situações, as impressões subjetivas desse indivíduo, usando os sentidos humanos e o senso de equilíbrio. Conforme Schütte (2005 apud JÚNIOR; BENASSI; AMARAL, 2011), "KE é uma metodologia para, sistematicamente, explorar os sentidos e sensações que as pessoas têm em relação a um produto e traduzi-los em parâmetros de design". De acordo com a Japanese Society of Kansei, KE é a "função integrada entre a mente e as várias funções que existem quando uma pessoa recebe e responde a estímulos". A interpretação mais resumida do KE diz respeito à psicologia do sentir. Hamada (1998 apud LOKMAN, 2010) descreve o método como uma função do cérebro relacionada com a coleta sensorial de informações, a percepção e cognição, a interpretação e "tradução" em sentimentos, emoções e intuição, o que também se pauta pelo julgamento e pela memória.

Para Nagamachi (2001 apud MARGHANI et al., 2011), existem três pontos fundamentais do KE: compreender com precisão o usuário; refletir e traduzir a compreensão do usuário em design de produto e criar um sistema e uma organização orientada para o design. 
A aplicação do KE está dividida em quatro etapas: Etapa 1: Escolher o domínio do produto - diz respeito à especificação do produto e ao perfil de público em análise; Etapa 2: Preencher o campo semântico - consiste na caracterização do produto em termos semânticos, para a definição das palavras KE, que são expressões, em geral adjetivos associados à percepção do produto; Etapa 3: Abranger o espaço das propriedades do produto - no campo das propriedades, é realizada a descrição e a compreensão do produto em análise; essas propriedades traduzirão o valor emocional do produto (cor, forma, estilo, preço, função, dentre outros); Etapa 4: Sintetizar - após a exposição do produto aos indivíduos, faz-se a coleta e a síntese dos dados através do estudo relacional das palavras $\mathrm{KE}$ com as propriedades do produto, bem como a validação e a construção do modelo conceitual do produto, ou ainda a definição de parâmetros projetuais.

Em 1996, Nagamachi propõe a classificação do KE em seis tipos, considerando as áreas envolvidas e as ferramentas incluídas. Em 2003, apresenta mais dois tipos a essa classificação. Os tipos de KE podem ser diferenciados pela prática das técnicas utilizadas: ora técnicas de cunho presencial, que exigem contato com o usuário e com o produto; ora técnicas virtuais, que possibilitam uma interação à distância entre tais atores. Além disso, a forma de apresentação do produto pode ser realizada fisicamente em modelos 2D, 3D, mock'ups, protótipos e até mesmo o produto já disposto no mercado.

Em se tratando de medição de variáveis intangíveis e com definições conflitantes, como no caso das emoções, o KE pode ser medido indiretamente. Nagamachi (2002) afirma que tais variáveis podem ser definidas como comportamentos e ações dos usuários frente ao produto. Trata-se de reações 
comportamentais; reações verbais; reações corporais; além de reações ou respostas fisiológicas. Para tanto, diversas abordagens de aferição de tais variáveis podem ser utilizadas no método KE. A abordagem aqui empregada dar-se-á através da escala diferencial semântico.

\subsubsection{Escala de diferencial semântico}

Criada por Charles Osgood, George Suci e Percy Tannenbaum em 1957, a escala de diferencial semântico é um método quantitativo que faz uso de palavras antônimas, dispostas na extremidade de uma escala numérica que define pesos, para coletar respostas de usuários acerca de como compreendem e reagem aos significados dos objetos, com base na avaliação de parâmetros pré-estabelecidos. Os dados são coletados por associações semânticas e cognitivas dos usuários em relação aos objetos, através dessas palavras. $\mathrm{Na}$ técnica, os entrevistados mostram a posição de sua atitude em relação ao objeto de pesquisa através da escala que polariza as palavras antônimas. No entanto, para o $\mathrm{KE}$, as palavras não devem ser necessariamente antônimas, mas sim negativas, como bonito e não bonito. Parte-se do conceito de que um objeto adquire significado quando uma palavra provoca uma resposta associada a ele.

As palavras opostas devem ter relação direta com o objeto que se destina à investigação. Elas são dispostas em um espaço semântico, composto por um número de "n" pesos, que retratam o significado afetivo do objeto. A variação da escala vai do pior estado ou menor valor de aceitação (valor mínimo da escala), ao estado neutro (valor mediano da escala utilizada), até o melhor estado ou maior valor de aceitação (valor máximo da escala). As escalas mais utilizadas para o método KE variam de 1 a 5 ou de 1 a 7 . Muitos pesquisadores 
defendem que 5 graus são suficientes para compilar as respostas, uma vez que essa extensão é a que melhor para o estilo de julgamento humano.

Aplicada ao método $\mathrm{KE}$, os antônimos da escala devem ser palavras que traduzem emoções (palavras KE). Entende-se que, através da apresentação do produto aos usuários (de modo físico ou virtual), associada à escala de diferencial semântico, os estímulos de entrada (imagem do produto) são simultaneamente processados pela razão e pela emoção. A imagem é construída fisiologicamente no olho humano, transmitida ao cérebro, que as decodifica; as informações percebidas são comparadas com o repertório (experiências vividas) do indivíduo e ativam as emoções ou sentimentos; essa reação emocional pode ser expressa fisiologicamente, por comportamento, gestos ou palavras. Para a engenharia $\mathrm{KE}$, quanto maior o número de estímulos (tato, visão, audição, paladar e olfato) em que o usuário estiver envolvido, melhor será a percepção e cognição do produto. Contudo, como defende a neurociência, a visão e a audição são os centros da nossa atenção consciente e podem remeter aos demais sentidos.

\subsubsection{Grupo focal}

Para a definição das palavras KE para aplicação da escala de diferencial semântico, torna-se necessária a aplicação de técnicas reflexivas sobre o objeto de estudo. Nesse caso, optou-se pelo grupo focal. A técnica de investigação por grupos focais possui caráter qualitativo. Morgan (1997 apud GONDIM, 2003) define grupos focais como uma técnica de pesquisa que coleta dados por meio das interações grupais ao se discutir um tópico especial sugerido pelo pesquisador. Como técnica, ocupa uma posição intermediária entre a 
observação participante e as entrevistas em profundidade. Segundo Gondim (2003), essa técnica pode ser caracterizada também como um recurso para se compreender o processo de construção das percepções, atitudes e representações sociais de grupos humanos.

Tendo em vista as premissas e os pressupostos da pesquisa realizada e os resultados pretendidos, o grupo focal tem intervenção direta do moderador, que deverá promover reflexões, com exploração de temas específicos. É utilizado para a resolução de problema que necessita, ao mesmo tempo, da aproximação com a população pesquisada e da compreensão dos símbolos, dos significados e significantes que ela utiliza na apreensão de uma dada realidade, em um determinado contexto. Compreende-se que a essência do grupo focal consiste justamente na interação entre os entrevistados e o moderador ou pesquisador, que objetiva colher dados a partir da discussão focada em tópicos específicos e diretivos. Na prática, a interação dos indivíduos no grupo focal ocorre, num primeiro nível, inserido nos domínios da psicologia social, seguida da psicologia cognitiva e da análise do discurso. As técnicas de grupo focal bem como da escala de diferencial semântico comportam-se de forma complementar ao método KE.

\section{Aplicação do método kansei no estudo emocional da estrutura vestimentar}

Aqui serão apresentadas as etapas do método $\mathrm{KE}$ e a aplicação das técnicas, dadas por meio da análise visual de estruturas vestimentares afro-baianas.

\section{Etapa 1 - Escolher o domínio do produto}

Nessa etapa, deve-se definir o perfil dos usuários e do produto, bem como a forma como ele será apresentado aos 
participantes da pesquisa. Para a definição dos usuários e dos produtos, tem-se de considerar a definição de variáveis. São variáveis independentes os estímulos que condicionam uma resposta, neste caso os elementos visuais que compõem a estrutura vestimentar (linha, cor, textura, padronagem, silhueta, forma e composição). Variável dependente é a emoção, o fator ou propriedade que é efeito de algo que foi estimulado. Variáveis controladas são fatores ou propriedades que poderiam afetar a variável dependente. No estudo, temse o estilo, a marca, o estilista, o fabricante e os aspectos comerciais; para os usuários tem-se a faixa etária da amostra.

Para a aplicação do grupo focal, foram selecionadas três estruturas vestimentares ( $A 1, A 2$ e $C 1)$ e, para o método $K E$, foram selecionadas quatro estruturas vestimentares $(C 1, C 2$, C3 e C4) - Figura 1. As roupas e acessórios das estruturas vestimentares selecionadas foram disponibilizadas por marcas baianas renomadas na criação e confecção de moda afro.

Cabe ainda, nessa etapa, a descrição técnica dos produtos avaliados, onde foram apresentados aos participantes da pesquisa, o tecido utilizado nas roupas, o material do calçado e acessórios, o tipo de estampa, a composição e cores das estampas visuais e táteis. 
Figura 1. Forma de apresentação das estruturas vestimentares.
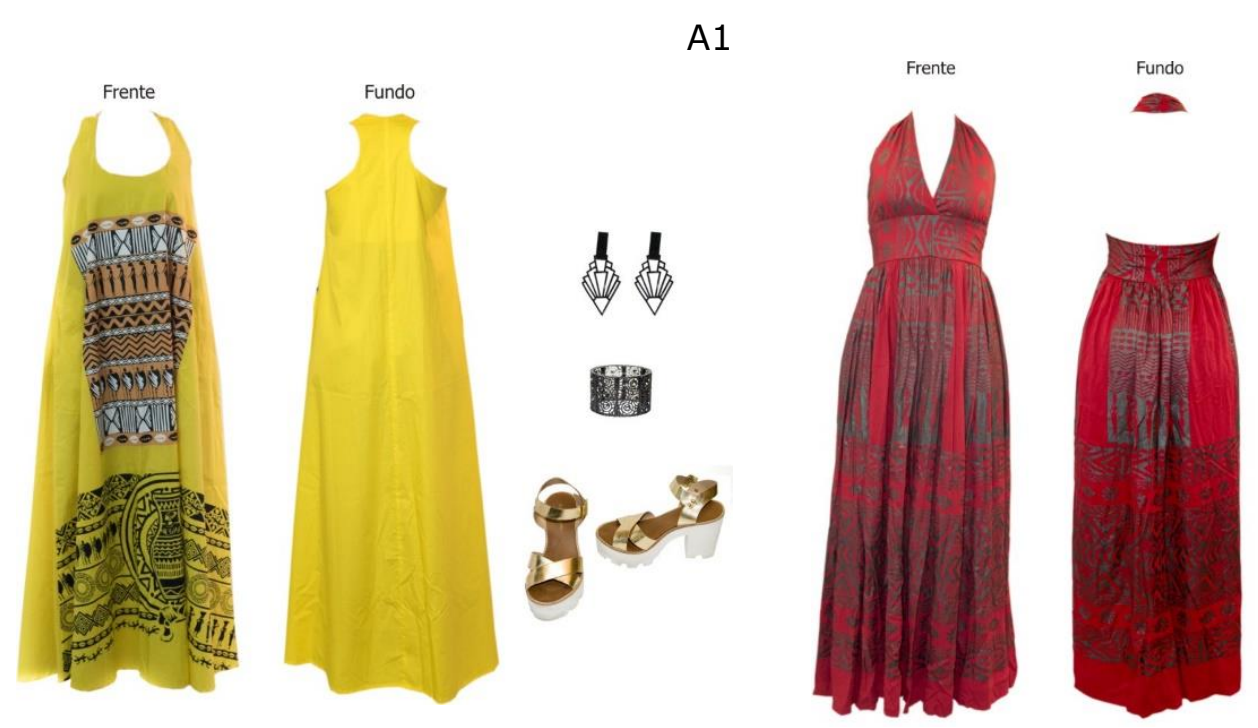

A2

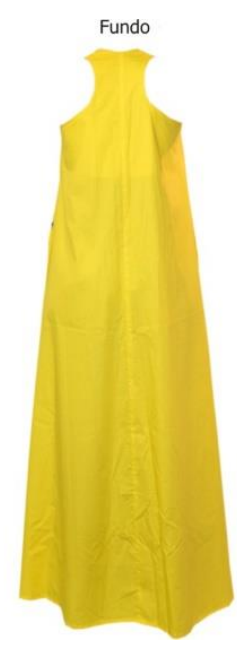

C1
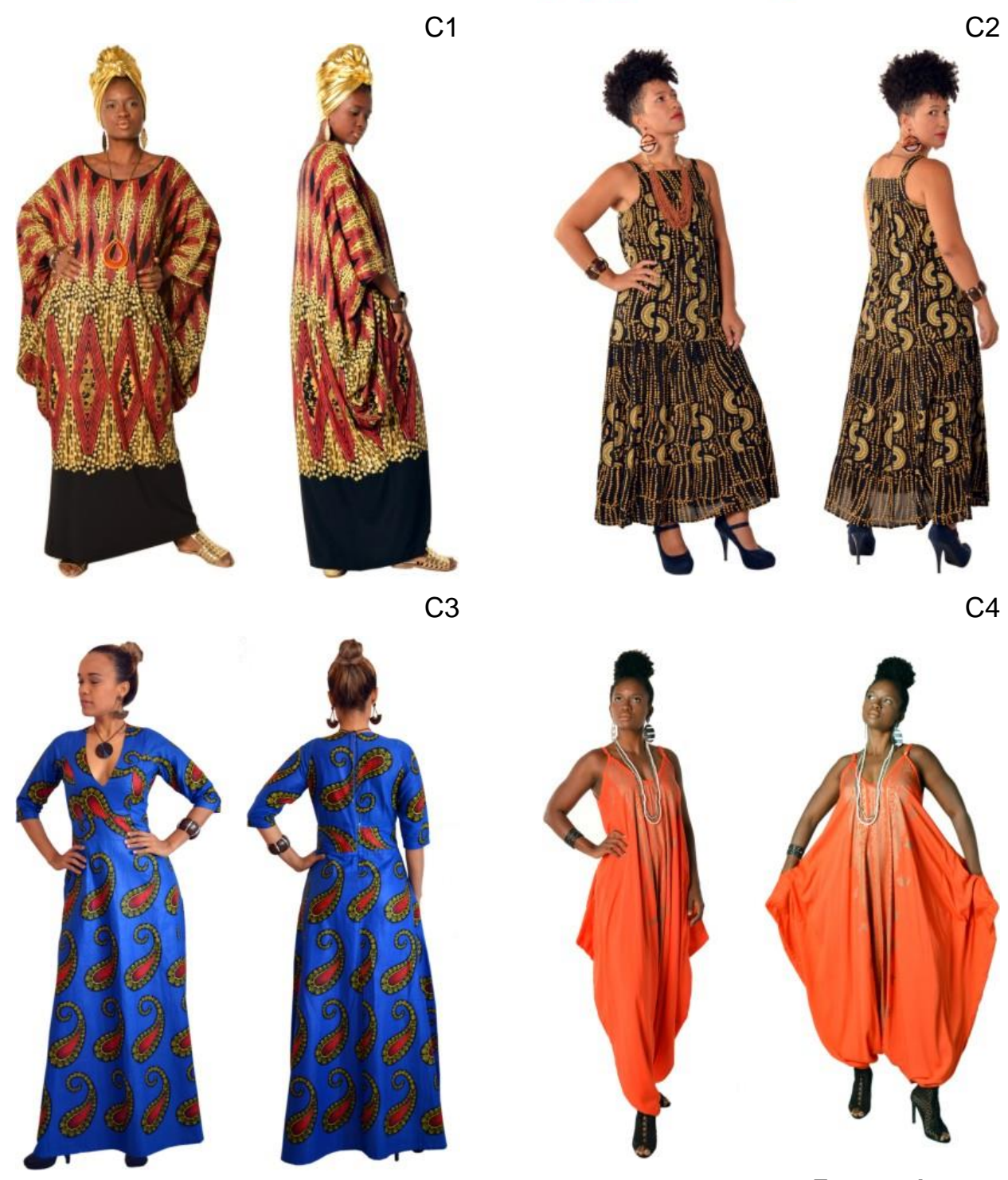

Fonte: Autores (2018). 


\section{Etapa 2 - Preencher o campo semântico}

Realizou-se a reunião de grupo focal que contou com a participação de seis mulheres e a pesquisadora que conduziu o grupo a refletir sobre moda, dividindo a reunião em seis momentos: apresentação do grupo e da pesquisa; debate para a compreensão do conceito de moda; adjetivação (por palavras) do conceito anteriormente construído; categorização dos adjetivos listados; análise visual das estruturas vestimentares $A 1, A 2$ e $C 1$, quando as participantes verbalizaram suas emoções; e, por fim, cada participante foi conduzido a justificar a escolha da estrutura vestimentar que mais agradou.

Uma vez listadas as palavras relacionadas pelo grupo focal (durante a reunião foram produzidos quadros com palavras citadas pelas participantes), e feita a consulta a revistas especializadas de moda e catálogos de tendência 2018, foram identificados seus sinônimos, através do dicionário on-line de sinônimos, dicionário etimológico e o dicionário analógico da língua portuguesa. Foram coletados 1800 sinônimos que, através do refinamento semântico (eliminação de palavras sem associação direta com objeto de estudo), foram reduzidos a 293 palavras, que foram então agrupadas. O agrupamento semântico tem por finalidade reduzir o número de palavras, reunindo-as por características de semelhança. Fez-se a eliminação de palavras conforme os filtros semânticos apresentados no Quadro 1, e a categorização (Quadro 2) associada aos elementos de design e à função do produto. Os elementos de design associados aos bens de moda são a linha (trajetória do olho humano, acabamento), cor, textura (sensação tátil relacionada ao material dos produtos), padronagem (estampa), silhueta (modelagem dos produtos no corpo), forma (composição geométrica dos produtos que compõem a estrutura vestimentar) e função 
(ergonômica, prática e simbólica). Foram agrupadas 75 palavras.

Quadro 1. Filtros semânticos para as palavras kansei.

\begin{tabular}{|c|c|c|}
\hline FILTRO & REMOÇÕES & DESCRIÇÃO \\
\hline & $\begin{array}{r}\text { Remoção de adjetivos } \\
\text { que não são } \\
\text { plausivelmente } \\
\text { relacionados ao objeto. }\end{array}$ & $\begin{array}{r}\text { Palavras que não podem ser metaforicamente } \\
\text { associadas a objetos inanimados (ex: animado e } \\
\text { imparcial). }\end{array}$ \\
\hline 2 & $\begin{array}{l}\text { Remoção de adjetivos } \\
\text { que descrevem reações. }\end{array}$ & $\begin{array}{r}\text { Palavras que se relacionam com juízo de valor } \\
\text { (ex: bom, ruim, fácil), ou possuem sentido vago } \\
\text { (ex: gosto e não gosto), isto é, palavras que } \\
\text { apenas descrevem o produto e não Ihe atribuem } \\
\text { valor emocional. }\end{array}$ \\
\hline 3 & $\begin{array}{r}\text { Remoção de adjetivos } \\
\text { ambíguos. }\end{array}$ & $\begin{array}{r}\text { Palavras que possibilitem mais de uma } \\
\text { interpretação conceitual (ex: claro - claro de cor } \\
\text { ou de luz?). }\end{array}$ \\
\hline 4 & $\begin{array}{l}\text { Remoção de adjetivos } \\
\text { não graduáveis. }\end{array}$ & $\begin{array}{l}\text { Aqueles que descrevem possíveis variações não } \\
\text { mensuráveis (ex: único, exclusivo, muito). }\end{array}$ \\
\hline 5 & $\begin{array}{l}\text { Remoção de adjetivos } \\
\text { que não correspondem } \\
\text { ao contexto da pesquisa. }\end{array}$ & $\begin{array}{l}\text { Alguns adjetivos são aplicáveis apenas pela } \\
\text { experimentação prolongada com o produto, não } \\
\text { podendo ser relatadas pela experiência visual ou } \\
\text { ainda adjetivos que não se associam de forma } \\
\text { perceptiva e direta ao objeto de estudo. }\end{array}$ \\
\hline
\end{tabular}

Fonte: Autores (2018).

Quadro 2. Agrupamento semântico das palavras coletadas associadas aos elementos de design.

\begin{tabular}{|c|c|c|c|c|c|}
\hline ELEMENTOS & \multicolumn{5}{|c|}{ PALAVRAS AGRUPADAS } \\
\hline Linha (4) & Agradável & Apropriada & Chique & Incrementado & \\
\hline Cor (5) & Alegre & Chamativo & Cativante & Forte & Intensa \\
\hline \multirow[t]{2}{*}{ Textura (8) } & Bem-estar & Delicadeza & Exótico & Pesada & Refinado \\
\hline & Resistente & Rudimentar & Ultrapassado & & \\
\hline \multirow{3}{*}{$\begin{array}{r}\text { Padronagem } \\
\text { (11) }\end{array}$} & Alinhado & Ancestralidade & Antiquado & Autenticidade & Criatividade \\
\hline & Enraizada & Excêntrico & Lembrança & Lúdica & Sobrecarregada \\
\hline & Tradição & & & & \\
\hline \multirow{3}{*}{$\begin{array}{r}\text { Silhueta } \\
\text { (11) }\end{array}$} & Aconchegado & Atrevido & Atraente & Corpulência & Deslumbrante \\
\hline & Elegância & Indecente & Moderno & Provocador & Sedutor \\
\hline & Segurança & & & & \\
\hline \multirow[t]{3}{*}{ Forma (13) } & Adaptada & Afetuoso & Atitude & Bonito & Extravagante \\
\hline & Inusitado & Original & Ousado & Passageiro & Respeito \\
\hline & Sensual & Simpatia & Singular & & \\
\hline \multirow[t]{5}{*}{ Função (23) } & Chocante & Conforto & Contentamento & Coragem & Determinação \\
\hline & Diferença & Étnico & Identidade & Imposição & Individualidade \\
\hline & Momentâneo & Personalidade & Pertencimento & Poder & Prestígio \\
\hline & Representativa & Requinte & Satisfação & Status & Tradição \\
\hline & Utilidade & Uniformização & Vinculo & & \\
\hline
\end{tabular}

Fonte: Autores (2018). 
Aqui, as palavras terão seus opositores associados, gerando os pares de palavras KE e a criação da escala semântica. Das palavras listadas no Quadro 2, houve ainda mais refinamento, considerando a manutenção daquelas associadas a cada elemento de design e sua relação mais direta com a estrutura vestimentar, compondo quinze pares de palavras KE (Quadro 3).

Quadro 3. Relação dos adjetivos com as estruturas vestimentares a serem analisadas.

\begin{tabular}{|c|c|}
\hline $\begin{array}{r}\text { ADJETIVO e PAR } \\
\text { OPOSITOR } \\
\end{array}$ & RELAÇÃO COM A ESTRUTURA VESTIMENTAR \\
\hline $\begin{array}{r}\text { Agradável } \\
\text { Não agradável }\end{array}$ & $\begin{array}{l}\text { Escala que se relaciona com o sentido de satisfação da estrutura } \\
\text { vestimentar para com os objetivos almejados pelo sujeito (seja o } \\
\text { de vestir, de estar bonito...). O deleite de apreciação. }\end{array}$ \\
\hline $\begin{array}{r}\text { Alegre } \\
\text { Não alegre }\end{array}$ & Relação de inspiração para a alegria. \\
\hline $\begin{array}{r}\text { Ancestral } \\
\text { Não ancestral }\end{array}$ & Faz relação com o pa \\
\hline $\begin{array}{r}\text { Atraente } \\
\text { Não atraente }\end{array}$ & Relação de atra \\
\hline $\begin{array}{r}\text { Autentica } \\
\text { Não autêntica }\end{array}$ & $\begin{array}{l}\text { Relaciona-se ao sentimento de autoria. A composição mostra-se, } \\
\text { mesmo que adquirida em loja, de forma autoral, não imitativa. } \\
\text { Promove um reconhecimento legítimo para algo ou alguém. }\end{array}$ \\
\hline $\begin{array}{l}\text { Confortável } \\
\text { Não confortável }\end{array}$ & $\begin{array}{l}\text { Busca relação de conforto físico e de se sentir bem ao se } \\
\text { visualizar no uso da estrutura vestimentar. Comodidade, } \\
\text { segurança e bem-estar. }\end{array}$ \\
\hline $\begin{array}{l}\text { Eleg } \\
\text { Não ele }\end{array}$ & Relação de bom gosto, com trato apurado e fino. \\
\hline $\begin{array}{r}\text { Extravagante } \\
\text { Não extravagante }\end{array}$ & $\begin{array}{r}\text { Relação de excentricidade ou exagero em algum } € \\
\text { pe }\end{array}$ \\
\hline $\begin{array}{r}\text { Exótica } \\
\text { Não exótica } \\
\end{array}$ & $\begin{array}{r}\text { Sentido de ser ou não nativo, relacionado ao que se tem como } \\
\text { raiz (matriz), diferenciado do cotidiano. }\end{array}$ \\
\hline $\begin{array}{r}\text { Moderna } \\
\text { Não moderna }\end{array}$ & $\begin{array}{r}\text { Sentido de atual, contemporâneo, pertencente ao contexto } \\
\text { vigente de estilo. }\end{array}$ \\
\hline $\begin{array}{r}\text { Personalidade } \\
\text { Não personalidade }\end{array}$ & $\begin{array}{r}\text { Sentido dado ao fato de a estrutura vestimentar representar } \\
\text { individualmente, trazer características próprias. }\end{array}$ \\
\hline $\begin{array}{r}\text { Pertença } \\
\text { Não pertença }\end{array}$ & $\begin{array}{r}\text { Sentido dado à ligação de } \\
\text { apro }\end{array}$ \\
\hline $\begin{array}{r}\text { Poder } \\
\text { Não poder }\end{array}$ & $\begin{array}{r}\text { Relacionado à possibilidade de a } \\
\text { força ou autoridade sup }\end{array}$ \\
\hline $\begin{array}{r}\text { Refinada } \\
\text { Não refinada }\end{array}$ & Dotado de delicadeza e sutileza. \\
\hline $\begin{array}{r}\text { Status } \\
\text { Não status } \\
\end{array}$ & us de ser e (ou) perter \\
\hline
\end{tabular}

Fonte: Autores (2018). 
Entende-se que os adjetivos selecionados e o seu par opositor refinam o julgamento individual e são importantes para a compreensão do valor emocional atribuído à estrutura vestimentar pelos usuários. Desse modo, foi diagramada a escala de diferencial semântico (Figura 2), com polaridade em uma variação de 1 ao 5, cujo número central (3) representa a neutralidade sobre a variável analisada, e as polaridades, 5 e 1, a avaliação de intensidade de prazer e desprazer, respectivamente.

Figura 2. Escala de diferencial semântico.

Agradável
Alegre
Ancestral
Atraente
Autentica
Confortável
Elegante
Extravagante
Exótica
Moderna
Personalidade
Pertença
Poder
Refinada
Status

$\begin{array}{llllll}5 & 4 & 3 & 2 & 1 \\ \bigcirc & \bigcirc & \bigcirc & \bigcirc & \bigcirc \\ \bigcirc & \bigcirc & \bigcirc & \bigcirc & \bigcirc \\ \bigcirc & \bigcirc & \bigcirc & \bigcirc & \bigcirc \\ \bigcirc & \bigcirc & \bigcirc & \bigcirc & \bigcirc \\ \bigcirc & \bigcirc & \bigcirc & \bigcirc & \bigcirc \\ \bigcirc & \bigcirc & \bigcirc & \bigcirc & \bigcirc \\ \bigcirc & \bigcirc & \bigcirc & \bigcirc & \bigcirc \\ \bigcirc & \bigcirc & \bigcirc & \bigcirc & \bigcirc \\ \bigcirc & \bigcirc & \bigcirc & \bigcirc & \bigcirc \\ \bigcirc & \bigcirc & \bigcirc & \bigcirc & \bigcirc \\ \bigcirc & \bigcirc & \bigcirc & \bigcirc & \bigcirc \\ \bigcirc & \bigcirc & \bigcirc & \bigcirc & \bigcirc \\ \bigcirc & \bigcirc & \bigcirc & \bigcirc & \bigcirc \\ \bigcirc & \bigcirc & \bigcirc & \bigcirc & \bigcirc \\ \bigcirc & \bigcirc & \bigcirc & \bigcirc & \bigcirc\end{array}$

$$
\begin{array}{r}
\text { Não-agradável } \\
\text { Não-alegre } \\
\text { Não-ancestral } \\
\text { Não-atraente } \\
\text { Não-autêntica } \\
\text { Não-confortável } \\
\text { Não-elegante } \\
\text { Não-extravagante } \\
\text { Não-exótica } \\
\text { Não-moderna } \\
\text { Não-personalidade } \\
\text { Não-pertença } \\
\text { Não-poder } \\
\text { Não-refinada } \\
\text { Não-status }
\end{array}
$$

Fonte: Autores (2018).

\section{Etapa 3 - Abranger o espaço das propriedades do produto \\ Aqui se define a forma de apresentação da estrutura vestimentar aos entrevistados. Entende-se que, para obter maior abrangência dos resultados da pesquisa, e por se aplicar o tipo II do método $\mathrm{KE}$, a estrutura vestimentar deverá}


ser apresentada através de fotografias digitais (frente e fundo, em corpos) (Figura 1).

Foram aplicados os questionários de mapeamento do perfil dos participantes, associado à escala de diferencial semântico através do link https://www.onlinepesquisa.com/s/1231c86, no período de 26 a 30 de março de 2018 (cinco dias). Foram obtidos um total de 382 questionários/escalas, com um total de 25.922 respostas. Dos 382 respondentes 71 não concluíram o preenchimento das escalas semânticas, sendo descartados os dados na pesquisa. Deste modo foram 311 questionários/escalas concluídos com 309 (99,4\%) deles em concordância com a pesquisa (questionários/escalas válidos para o teste) e $2(0,6 \%)$ dos questionários/escalas em discordância com a pesquisa.

\section{Etapa 4 - Sintetizar}

Cabe aqui a leitura e a interpretação dos dados coletados, considerando a relação emocional com o produto. A extratificação da análise deu-se pela variável etária dos usuários (variável controlada): Grupo 1 - de 25 a 34 anos; Grupo 2 - de 35 a 44 anos; e Grupo 3 - de 45 a 54 anos. Cabe salientar a relevância da análise dos dados por grupos etários tendo em vista que a produção em moda é comumente segmentada por faixa etária.

A descrição, compreensão e interpretação da percepção emocional da estrutura vestimentar afro-baiana através de elementos de design, foi feita através de análise descritiva e estatística da percepção emocional por grupos etários, objetivando identificar a estrutura vestimentar mais bem avaliada por faixa etária; e identificar as emoções mais bem avaliados por estrutura vestimentar por faixa etária.

Utilizou-se como métodos de análise estatística o teste de Kruskal-Walis (KW) (HOLLANDER; WOLFE, 1999) e o teste comparações múltiplas de Nemenyi (NEMENYI, 1963). 
O grupo 1 (25 a 34 anos) apresenta a ordem decrescentes de avaliação positiva para $\mathrm{C} 1, \mathrm{C} 4, \mathrm{C} 2$ e C3, e a sequência decrescente por impressão negativa para C2, C3, C4 e C1. A percepção emocional positiva associou-se predominantemente aos aspectos funcionais dos produtos, em sequência à cor e padronagem. E a percepção emocional negativa associada a forma, silhueta, textura e silhueta (Quadro 5).

Quadro 5. Síntese da percepção emocional das estruturas vestimentares e conversão das palavras KE em elementos de design ( 25 a 34 anos).

\begin{tabular}{|c|c|c|c|c|}
\hline ESTRUTURA & $\begin{array}{r}\text { DESCRITORES } \\
\text { POSITIVOS }\end{array}$ & $\begin{array}{r}\text { ELEMENTOS } \\
\text { DE DESIGN } \\
\text { ASSOCIADO }\end{array}$ & $\begin{array}{r}\text { DESCRITORES } \\
\text { NEGATIVOS }\end{array}$ & $\begin{array}{r}\text { ELEMENTOS } \\
\text { DE DESIGN } \\
\text { ASSOCIADO }\end{array}$ \\
\hline \multirow{3}{*}{$\mathrm{C} 1$} & Personalidade & Função & Não extravagante & Forma \\
\hline & Confortável & Função & Não moderna & Silhueta \\
\hline & Autentica & Padronagem & Não exótica & Textura \\
\hline \multirow{3}{*}{$\mathrm{C} 2$} & Personalidade & Função & Não extravagante & Forma \\
\hline & Confortável & Função & Não atraente & Silhueta \\
\hline & Autentica & Padronagem & Não refinada & Textura \\
\hline \multirow{3}{*}{$\mathrm{C} 3$} & Alegre & Cor & Não extravagante & Forma \\
\hline & Personalidade & Função & Não ancestral & Padronagem \\
\hline & Confortável & Função & Não exótica & Textura \\
\hline \multirow{3}{*}{ C4 } & Personalidade & Função & Não status & Função \\
\hline & Confortável & Função & Não extravagante & Forma \\
\hline & Autentica & Padronagem & Não refinada & Textura \\
\hline $\begin{array}{r}\text { MÉDIA DAS } \\
\text { ESTRUTURAS }\end{array}$ & Personalidade & Função & Não extravagante & Forma \\
\hline
\end{tabular}

Fonte: Autores (2018).

O grupo 2 (de 35 a 44 anos) indicou positivamente em ordem decrescente as estruturas C4, C1, C2 e C3, e negativamente C2, C3, C1 e C4. A percepção emocional 
positiva associou-se predominantemente aos aspectos funcionais dos produtos, em sequência à cor e padronagem. E a percepção emocional negativa associada a forma, silhueta, textura, padronagem e silhueta (Quadro 6).

Quadro 6. Síntese da percepção emocional das estruturas vestimentares e conversão das palavras KE em elementos de design ( 35 a 44 anos).

\begin{tabular}{|c|c|c|c|c|}
\hline ESTRUTURA & $\begin{array}{l}\text { DESCRITORES } \\
\text { POSITIVOS }\end{array}$ & $\begin{array}{c}\text { ELEMENTOS DE } \\
\text { DESIGN } \\
\text { ASSOCIADO } \\
\end{array}$ & $\begin{array}{l}\text { DESCRITORES } \\
\text { NEGATIVOS }\end{array}$ & $\begin{array}{c}\text { ELEMENTOS DE } \\
\text { DESIGN } \\
\text { ASSOCIADO } \\
\end{array}$ \\
\hline \multirow{3}{*}{ C1 } & Personalidade & Função & Não atraente & Silhueta \\
\hline & Confortável & Função & Não refinada & Textura \\
\hline & Autentica & Padronagem & Não extravagante & Forma \\
\hline \multirow{3}{*}{$\mathrm{C} 2$} & Personalidade & Função & Não refinada & Textura \\
\hline & Confortável & Função & Não atraente & Silhueta \\
\hline & Autentica & Padronagem & Não moderna & Silhueta \\
\hline \multirow{4}{*}{ C3 } & Confortável & Função & Não ancestral & Padronagem \\
\hline & Alegre & Cor & Não refinada & Textura \\
\hline & Personalidade & Função & Não atraente & Silhueta \\
\hline & & & Não exótica & Textura \\
\hline \multirow{4}{*}{ C4 } & Confortável & Função & Não refinada & Textura \\
\hline & Personalidade & Função & Não elegante & Silhueta \\
\hline & Autentica & Padronagem & Não ancestral & Padronagem \\
\hline & & & Não atraente & Silhueta \\
\hline $\begin{array}{l}\text { MÉDIA DAS } \\
\text { ESTRUTURAS }\end{array}$ & Confortável & Função & Não refinada & Textura \\
\hline
\end{tabular}

Fonte: Autores (2018).

Já o grupo 3 (de 45 a 54 anos), apresentou avaliação positiva para C1, C4, C2 e C3, em ordem decrescente. E a sequência decrescente por impressão negativa tem-se C2, C3, C1 e C4. A percepção emocional positiva associa-se aos 
aspectos funcionais, linha, forma, cor e silhueta. E a percepção emocional negativa associada a padronagem, função, textura, forma, silhueta, textura (Quadro 7).

Quadro 7. Síntese da percepção emocional das estruturas vestimentares e conversão das palavras $\mathrm{KE}$ em elementos de design (45 a 54 anos).

\begin{tabular}{|c|c|c|c|c|}
\hline ESTRUTURA & $\begin{array}{l}\text { DESCRITORES } \\
\text { POSITIVOS }\end{array}$ & $\begin{array}{c}\text { ELEMENTOS } \\
\text { DE DESIGN } \\
\text { ASSOCIADO }\end{array}$ & $\begin{array}{c}\text { DESCRITORES } \\
\text { NEGATIVOS }\end{array}$ & $\begin{array}{l}\text { ELEMENTOS } \\
\text { DE DESIGN } \\
\text { ASSOCIADO }\end{array}$ \\
\hline \multirow{4}{*}{ C1 } & Confortável & Função & Não atraente & Silhueta \\
\hline & Autentica & Padronagem & Não ancestral & Padronagem \\
\hline & Personalidade & Função & Não refinada & Textura \\
\hline & & & Não status & Função \\
\hline \multirow{4}{*}{$\mathrm{C} 2$} & Confortável & Função & Não ancestral & Padronagem \\
\hline & Agradável & Linha & Não refinada & Textura \\
\hline & Personalidade & Função & Não poder & Função \\
\hline & & & Não status & Função \\
\hline \multirow{5}{*}{ C3 } & Alegre & Cor & Não ancestral & Padronagem \\
\hline & Personalidade & Função & Não atraente & Silhueta \\
\hline & Agradável & Linha & Não pertença & Função \\
\hline & Extravagante & Forma & & \\
\hline & Moderna & Silhueta & & \\
\hline \multirow{5}{*}{ C4 } & Confortável & Função & Não status & Função \\
\hline & Personalidade & Função & Não refinada & Textura \\
\hline & Alegre & Cor & Não atraente & Silhueta \\
\hline & Extravagante & Forma & Não pertença & Função \\
\hline & & & Não poder & Função \\
\hline $\begin{array}{l}\text { MÉDIA DAS } \\
\text { ESTRUTURAS }\end{array}$ & Confortável & Função & Não ancestral & Padronagem \\
\hline
\end{tabular}

Fonte: Autores (2018). 
As análises, descritiva e estatísticas, mantiveram resultados próximos no que tange às avaliações emocionais positivas das estruturas vestimentares. Quanto aos descritores (palavras KE) negativos foram observadas, através da análise estatística uma variação na ordem de relevância dos descritores, porém a manutenção dos mesmos descritores citados. Deste modo compreende-se que os descritores emocionais, positivos e negativos, podem ser facilmente convertidos em requisitos projetuais para 0 desenvolvimento de novos bens de moda.

\section{Conversão da percepção emocional em requisitos projetuais}

Compreende-se que o projeto por requisitos emocionais contempla demais requisitos de projeto, como a funcionalidade, que se traduzem na construção de elementos de design favoráveis ao atendimento das necessidade e desejos dos usuários. A interação afetiva de prazer sustenta projetos direcionados às relações emocionais positivas entre produtos e usuários. Sintetiza-se deste modo que para as estruturas vestimentares afro-baianas a percepção positiva dos aspectos funcionais é mais acentuada através de emoções que evocam a personalidade e o conforto. Cor e padronagem são elementos de design que também traduzem percepções emocionais positivas como alegria e autenticidade. A padronagem, para os grupos 1 e 2, que contemplam de 25 a 44 anos, é um elemento de design expressivamente percebido e avaliado positivamente. Porém a padronagem não traduz emoção associada à ancestralidade das peças (descritor emocional positivo indicado apenas na avaliação da estrutura A1, na análise estratística), pode-se incitar a afirmação de que os traços ancestrais, tão presentes nas roupas e acessórios 
afro-baianos, já foram incorporados à própria cultura do vestir do povo. Uma afirmação de pertencimento identitário de padrões gráficos étnicos e que independe da faixa etária.

Os elementos de linha, forma e silhueta, para a faixa etária do grupo 3, expressam emoções positivas de agradabilidade, extravagância e modernidade. O mesmo não foi observado nos demais grupos estudados. A textura remete aos sentimentos de não refinamento e o não exoterismo das estruturas vestimentares, havendo indicação negativa em todas as estruturas analisadas pelos três grupos. Apenas o grupo 1 indicou, para as quatro estruturas vestimentares analisadas a percepção emocional de não extravagante, associada à forma. A silhueta que remete à percepção negativa para modernidade e atraente. As estruturas em silhueta triângular, ampulheta e retangular mostraram-se menos atraente na percepção emocional.

Entende-se que os sentimentos negativos associados à textura, forma e silhueta poderão ser replicados em demais estruturas vestimentares afro-baianas pois as mesmas tendem a possuir padrões visuais semelhantes quanto a estes elementos de design, que caracterizam, principalmente, a roupa ampla, volumosa, sem silhueta definida e com texturas que tendem à rusticidade de materiais. A percepção emocional de não status, associada à função da estrutura vestimentar, é destacada nas estruturas $C 4$, pelos grupos $1 \mathrm{e}$ 3; e C2 pelo grupo 3. O grupo 3 ainda indicou emoções negativas relacionadas à função (não poder e não pertença), levando a uma conclusão incipiente de que os usuários na faixa etária de 45 a 54 anos não se apropriam os elementos visuais do vestir afro-baiano, em oposição aos demais grupos etários.

Vimos que os atributos perceptíveis dos produtos, traduzidos em seus elementos de design, influenciam a 
atração emocional pelos mesmo, sendo possível mapear modelos emocionais de interação dos usuários com os bens de moda, e, consequentemente, conduzir o projeto de produtos à significação emocional. Tomando como base esta premissa conclusiva da pesquisa, e comparando os dados tabulados e sintetizados da avaliação emocional das quatro estruturas vestimentares utilizadas no teste, pode-se definir requisitos base para o desenvolvimento de novas estruturas vestimentares. Deste modo considera-se como requisitos base:

- Linha - manter elementos visuais que permitam a verticalização da estrutura vestimentar como o comprimento alongado das roupas, brincos $e$ colares;

- Cor - evitar se restringir aos tons terrosos e preto. Propõe-se o uso de cores vibrantes e em harmonia com a composição de toda a estrutura vestimentar;

- Textura - Evitar o excesso de textura visual nas composições;

- Padronagem - explorar grafismos étnicos com estampas corrida e localizada; explorar padrões táteis em acessórios como trançado e recortes;

- Silhueta - buscar por silhueta que valorize o corpo, não necessariamente com a marcação de cintura (silhueta ampulheta);

- Forma - Propor extravagância das formas, seja através da modelagem da roupa, estrutura do tecido, uso de aviamentos, corte com decote, composição de acessórios diferenciados, para o grupo etário de 25 a 34 anos, não indicando aos grupos mais velhos;

- Função - primar pelo conforto através da modelagem e da fluidez do tecido e dos acessórios; 
buscar elementos que traduzam personalidade na composição (cor, modelagem e padronagem diferenciada de padrões convencionais, podem auxiliar na percepção de personalidade; bem como acessórios diferenciados como o turbante).

Para a implementação adequada dos requisitos foram criadas fichas que relacionam as emoções e elementos de design aos requisitos citados, deste modo a equipe de projeto deve ter a definição da emoção almejada na relação do usuário com o produto. Uma vez selecionada a emoção, cabe a compreensão do requisito aplicando-o através do elemento de design. Por exemplo, querendo tronar a relação visual dos usuários com a estrutura vestimentar agradável tem-se que atender aos requisitos através da repetição e ritmo verticalizados dos desenhos da estampa ou ainda da modelagem; ou a gradação cromática e de forma, criando uma trajetória visual da estrutura vestimentar (linha elemento de design).

\section{Conclusão}

Como foi visto, a emoção faz parte da condição humana, assim como seus aspectos físicos, fisiológicos e cognitivos, bem como da compreensão do sujeito que se modela numa perspectiva de interações contemporâneas, que é um ser sensível, conduzindo a relação com os produtos sob a luz da emoção. Para projetos pautados na emoção, a interação do homem com os produtos deve ser avaliada pelo prazer, atendendo a requisitos projetuais que conduzam ao despertar de emoções e promovam uma interação afetiva.

A percepção emocional se associa ainda à capacidade humana de identificação, reconhecimento e lembrança de elementos sensoriais dos produtos, e dos contextos de vida. 
Desse modo, cabe ao projeto dos produtos de hoje transcender a efêmera relação funcional que conduz ao conforto físico e cognitivo, e absorver a relação emocional com os sujeitos, pois a emoção constitui parte integrante e indissociável dos fatores humanos e da prática do designer.

O método KE auxilia no processo de relatar a compreensão das emoções de maneira integrada, a partir dos significados que os usuários conferem aos produtos. Esses significados ou emoções, que são condicionados às relações sociais e culturais que se estabelecem no íntimo dos usuários, podem ser compreendidos e convertidos em requisitos projetuais para o desenvolvimento de novos produtos. $O$ método apresentado, associado às técnicas da escala de diferencial semântico e reunião de grupo focal, é considerado eficiente e, possivelmente, integrado à prática projetual do designer.

\section{Notas}

1 A emoção diz respeito a um estado de corpo (função volitiva), é "contagiosa" e passageira. Para Desmet (2002), a emoção é um estado afetivo agudo e intencional e, desse modo, é conceituada por um estado afetivo dado a um estímulo (objeto ou evento) relacionado intencionalmente com o homem e que possui duração, com início e fim bem definidos, diferenciando-se, assim, do sentimento.

${ }^{2} \mathrm{O}$ sentimento é perene, duradouro. Compõe a memória permanente, ativada ao se relacionar cognitivamente com um dado objeto ou evento.

3 O repertório emocional é configurado quando todas as experiências vividas ficam gravadas no sistema nervoso humano como inclinações inatas e automáticas do coração (GOLEMAN, 1995). 


\section{REFERÊNCIAS}

BARTHES, Roland. Sistema da moda. trad. do francês por Lineide do Lago Salvador Mosca. SP: Cia. Ed. Nac./Ed. da Universidade de São Paulo, 1979, 328p.

BALDUINO, Mariana Araújo. Aplicação da metodologia de engenharia Kansei na análise de consumo de chás. 2012. 90 f. Dissertação (Mestrado) - Ciências do Consumo e Nutrição, Geociências, Ambiente e Ordenamento do Território, Universidade do Porto, Porto, 2012.

CIDREIRA, Renata Pitombo. Os Sentidos da Moda. São Paulo: Annablume, 2006. 146 p.

DAMÁSIO, António R. O erro de Descartes: Emoção, razão e o cérebro humano. São Paulo: Companhia das Letras, 1996. Tradução de: Dora Vicente e Georgina Segurado.

DESMET, P. M. A.; HEKKERT, P.. The basis of product emotions. In: W.green And P. Jordan (eds.), Pleasure With Products, Beyond Usability, London, p.60-68, 2002.

FONTOURA, Antônio M.; ZACAR, Cláudia R. Hasegawa. Quando o design mexe com a gente. In: abc Design. Ed n. 25. Curitiba, 2008. ISSN 1676-5656.

GONDIM, Sônia Maria Guedes. Grupos focais como técnica de investigação qualitativa: desafios metodológicos. In: PAIDÉIA, 12., 2003, Salvador: UFBa, p. 149 - 161.

GOLEMAN, Daniel. Inteligência emocional: a teoria revolucionária que redefine o que é ser inteligente. Rio de Janeiro: Objetivo, 1996. 383 p. Tradução de: Marcos Santarrita.

JUNIOR, L. D. F.; BENASSI, J. L. G.; AMARAL, D. C.. Kansei Engineering na gestão ágil de projetos de novos produtos: potencialidades e desafios. In: GESTÃO DA PRODUÇÃO, OPERAÇÕES E SISTEMAS. Ano 6, 2011. p. 59 - 76.

JORDAN, Patrick $W$. Human factors for pleasure in product use. Applied Ergonomics, [s. L.], v. 29, n. 1, p.22-33, nov. 1996.

LOKMAN, Anitawati Mohd. DESIGN \& EMOTION: THE KANSEI ENGINEERING METHODOLOGY. In: Revista Faculty of Computer and Mathematical Sciences, 2010, Malaysia: Universiti Teknolgi Mara, 2010. p. 1 - 14. ISSN 2231-7473.

MARGHANI, $V$ el et al. Kansei Engineering: metodologia orientada ao consumidor para suporte a decisão de projeto. $8^{\circ}$ Congresso Brasileiro De Gestão De Desenvolvimento De Produto. 12, 13, 14 de setembro de 2011. Porto Alegre-RS, 2011. p 1-13.

MYERS, David G. Psicologia. Rio de Janeiro: Ftc, 2006. Tradução de Eduardo Jorge Custódio da Silva; Maria dos Anjos Santos Rouch.

NAGAMACHI, Mitsuo. Kansei Engineering as an ergonomic consumer-oriented technology for product development. Applied Ergonomics, Hiroshima, p.289-294, 2002. Dept. of Kansei Ergonomics. Hiroshima International University. 
NIEMEYER, Lucy. Design atitudinal: Uma abordagem projetual. In: MONT'ALVÃO, Claudia; DAMÁZIO, Vera (Org.). Design ergonomia emoção. Rio de Janeiro: Faperg Mauad, 2008. Cap. 3. p. 49-64.

NORMAN, Donaldo A.; DEIRÓ, Tradução Ana. Design emocional: Por que adoramos (ou detestamos) os objetos do diaa-dia. Rio de Janeiro: Racco, 2008. 278 p. 